Original Research Paper

\title{
Economic Analysis of Honey Production in Chitwan District, Nepal
}

\author{
${ }^{1}$ Sushmita Bhatta, ${ }^{1}$ Suraksha Baral and ${ }^{2}$ Jay Prakash Datta \\ ${ }^{1}$ Department of Agriculture, Agriculture and Forestry University, Nepal \\ ${ }^{2}$ Department of Agriculture Economics, Agriculture and Forestry University, Nepal
}

Article history

Received: 13-07-2020

Revised: 22-12-2020

Accepted: $30-12-2020$

Corresponding Author:

Sushmita Bhatta

Department of Agriculture,

Agriculture and Forestry

University, Nepal

Email: agrisushmita55@gmail.com

\begin{abstract}
Apiculture is being practiced in Nepal from time immemorial. Economic analysis of honey production in Chitwan district was carried out to analyze profitability along with resource use efficiency in different enterprise system of beekeeping. The Categorization of beekeepers was done according to the number of beehives as small, medium and large. A total of 60 beekeepers were proportionately selected which included 25 small, 24 medium and 11 large scale beekeepers. Descriptive and other statistical tools were analyzed with the help of MS Excel and SPSS. Multiple regression analysis for production function was done using the Cobb-Douglas model in STATA. It was found that the average number of beehives owned by small, medium and large enterprises was 37.08, 69.71 and 171.55 respectively. The overall average productivity of honey was 23.71 kgs/hive. The average Production cost per hive was NRs.4746.62 with the average profit of NRs 3270.01. The average gross margin of the beekeeping was found in NRs.3642.97 with a significant scale effect. Similarly, the net margin per hive was found NRs 3270.17 on average. The overall benefit-cost ratio was found to be 1.65 which also reflected the economy of scale. The cost of comb foundation, marketing and labor showed a positive significant effect on gross return from honey production. The return to scale was found to be 0.63 which showed a decreasing return to scale. Similarly, the cost of migration was overutilized whereas cost on labor, feed, comb foundation and marketing were underutilized. Beekeeping is a minimal investment business with high returns if efficient inputs are used.
\end{abstract}

Keywords: Beekeepers, Economy of Scale, Resource Use, Efficiency

\section{Introduction}

Beekeeping or honey harvesting is an extremely old practice in Nepal. Since many years, farmers have been involved in traditional beekeeping in various parts of hilly and terai plains of Nepal. For poor and vulnerable communities, even without access to land, beekeeping has made a significant contribution to their livelihood security (SAWTEE, 2015). Beekeeping offers farmers to earn income with minimal start-up investment, yielding profits within the first year of operation ICIMOD, 2017 (Verma, 1990). Beekeeping products include; honey, beeswax, royal jelly, propolis and pollination services for plants which are very rich in nutrition and health benefits and can be marketed well. Apart from providing regular income to the family in terms of honey production, it offers a complementary source of income for farmers from crop pollination by increasing yield and quality (SAWTEE, 2015).

The potential benefits of honey are manifold. The NTIS estimated that more than 53,000 farmers are involved in honey production (MoCS, 2010). In recent years, modern beekeeping has also been extended. Nepal has the potential to produce more than 10,000 tons of honey per year (Bhattarai et al., 2013). As mentioned in (MoAD, 2016/17), there are 240,000 hives in Nepal which are in state of expansion this year. Nepali honey has both domestic and international market if quality is assured timely. The leading honey companies calculates that if honey consumption increased by 0.1 kilogram per capita then total demand for honey in the domestic market would be about 2,500 tons per year (Bhattarai et al., 2013). Moreover, there is an ample room to boost the production of honey in Nepal by facilitating with technical 
guidance, adequate supply of resources with credit facilities to rural emerging farmers.

Chitwan foothills and plains are high potential areas for commercial beekeeping and can surely uplift economic condition of engaged farmers. Nepal's honey remains distinct in flavor due to the unique climatic conditions and flora prevalent in Nepal. Despite of immense potential i.e., about 10,000 metric ton/year, the average honey produced this year is 3980 metric tons (MoAD, 2016/17). Honey yield has increased with increased number of colonies in Nepal (Aryal et al., 2015). Honey production requires high initial capital inputs and strict seasonal management practices and low economic condition of local people and out migration of active populations is hindering the beekeeping business. Because of which, the average yield of honey is far below than the potential yield. The low level of production could be attributed to inefficient use of resources and lack of technical efficiency of farmers. Similarly, Honey produced at local level is lacking its market due to high price gap between international and local products and local honey are not getting reasonable price even for being higher in quality.

In recognition of the looming market crisis for local honey, some of the efforts had been done by government which is not enough to motivate the farmers to adapt commercial apiculture. Thus, within this context, we evaluated the economics of honey production and factors affecting it with a view to further improve the level of productivity. Economics of production is important from perspective of increasing output especially for marginal farmers and is also essential for competitiveness and profitability. It will also examine the allocation of resources and suggest the efficient use of it. There had been relatively lesser research regarding economics of honey production in Chitwan district. In order to know the various economics part of beekeeping enterprise in Chitwan, scientific study was deemed necessary and done.

\section{Materials and Methods}

\section{Study Area and Sampling Procedure}

Chitwan district was purposely selected for the study. Selection was done based on the potentiality of honey production and all the beekeepers who has harvested honey for more than a year were the target population for this study. On the basis of the information regarding the number of hives in the study area, total population of the beekeepers was divided into 3 categories. Total 60 samples were chosen from the study area in proportionate manner which included 25 small scale, 24 medium scale and 11 large scale beekeepers.

\section{Data Collection and Analysis}

The primary data for the study were collected from 0the prime farmers of the site. Secondary data were collected from various relevant literatures of national and international publications, government reports, proceedings, books and websites. The collected data on local units of measurements were standardized into the scientific one. Descriptive analysis of the obtained data was done by using SPSS and MS Excel and qualitative analysis was done in STATA 12 software.

Benefit cost analysis was carried out by using formula:

$$
\begin{aligned}
& \mathrm{B} / \mathrm{C} \text { ratio }=\text { Gross return }(\text { NRs. /hive)/Total } \\
& \text { cost }(\mathrm{NRs} \text {. /hive) } \\
& \text { Note: }[1 \mathrm{USD}=\text { NRs. } 118]
\end{aligned}
$$

Cobb-Douglas production function was used to find the productivity and resource-use efficiency:

$$
Y=a X 1 b 1 X 2 b 2 \times 3 b 3 e u
$$

The function was transformed into the log-linear form:

$$
\begin{aligned}
& \ln Y=\ln a+b 1 \ln X 1+b 2 \ln X 2 \\
& +b 3 \ln X 3+b 4 \ln X 4+b 5 \ln X 5
\end{aligned}
$$

Where:

$\begin{array}{lll}Y & = & \text { Gross return (NRs/hive) } \\ \ln & = & \text { Natural logarithm } \\ X 1 & = & \text { Cost on human Labor (NRs/hive) } \\ X 2 & = & \text { Cost on comb foundation } \\ & & (\text { NRs/hive) } \\ X 3 & = & \text { Cost of migration (NRs/hive) } \\ X 4 & = & \text { Cost of marketing (NRs/hive) } \\ X 5 & = & \text { Cost of artificial feed (NRs/hive) } \\ e & = & \text { Base of natural logarithm } \\ u & = & \text { Random disturbance term } \\ a & = & \text { Constant } \\ b 1, b 2, b 3, b 4, b 5 & = & \text { Represent Coefficients of respective } \\ & & \text { variables }\end{array}$

The efficiency of resource use was calculated as:

$$
r=M V P / M F C
$$

Where:

$$
\begin{aligned}
& r \quad=\text { Efficiency ratio } \\
& M V P=\text { Marginal value product of a variable input } \\
& M F C=\text { Marginal factor cost }
\end{aligned}
$$

\section{Results and Discussion}

\section{Socio-Demographic Characteristics of Categorical Variable}

The responses about sex, ethnicity, occupation, education status of the household head and migration status of the household were collected and described in the Table 1. Out of the total respondent, 93.3 and $6.70 \%$ were male and female beekeepers respectively. Male 
population was found higher in each category i.e., 92, 91.70 and $100 \%$ in small, medium and large-scale beekeepers. From the Table 1, it is evident that Janajatis $(55.00 \%)$ were dominating group among respondents followed by Brahmin/Chhetri and Dalits. In total, beekeeping was the major occupation for every respondent which came under agriculture unlike the result shown by (Devkota et al., 2016) that showed only $57 \%$ in agriculture. Besides agriculture, beekeepers had income from service $(13.3 \%)$, business $(23.30 \%)$ and remittance $(16.7 \%)$. Regarding the education status, whole respondents were literate. Brain drain is the major problems that are reducing the availability of labor in agriculture (Kattel and Sapkota, 2018). The migration status was assessed. Out of total respondents $40 \%$ had migrated at least one family member outside the country whereas $60 \%$ were dedicated in beekeeping enterprise.

\section{Socio-Economic Characteristics of Continuous Variable}

The socio-economic information regarding age, years of experience, Household size, male and female members, economically active population, dependency ratio, hive numbers were presented in Table 2.

The average age of the beekeepers was 40.4, 41.67 and 42.91 years of small, medium and large scale respectively. Beekeepers were of minimum 19 years old and maximum up to 66 years old. However, there was no significant difference in the age of beekeepers among different category. The mean experience was found to be 9.43 years ranging from 1 year to 24 years which is contrast to (Abebe, 2009). From the Table 2, we found mean experience of $6.2,9.71,16.18$ years in small, medium and large-scale beekeepers respectively. There is statistical significance at $1 \%$ level.

The average household size was found to be 5.4, 5.58 and 6 for small, medium and large-scale beekeepers which is higher than average household size in Nepal (Central Bureau of Statistics, 2016). The household size ranged from 3 to 12 among the respondents. The average male members in small, medium and large category were found to be $2.76,2.92$ and 3.45 respectively. Similarly, females were 2.64, 2.67 and 2.55 in small, medium and large-scale beekeepers respectively.

In the study area the average economically active members were 3.68 in small scale, 3.71 in medium scale and 4.27 in large scale beekeepers along with the dependency ratio of $0.59,0.66$ and 0.37 in small, medium and large-scale beekeepers respectively. The average dependency of the study area was 0.58 which means 100 active populations had to fulfill the basic requirement of 58 dependent populations.

The total number of hives of small scale was 37.08, medium scale was 69.71 and large scale was 171.55 . The difference between the mean of three categories was significant statistically at $1 \%$ level.

\section{Cost of Production}

The cost of honey production per hive per year is presented in Table 3. The total cost of honey production per hive per year was NRs. 5398.93 in small scale, NRs 4661.84 in medium scale and NRs 3449.03 in large scale enterprise. The total variable cost shares $84.9,81.16$ and $70.46 \%$ of the total cost in small, medium and large-scale enterprise.

Table 1: Socio-economic characteristics of categorical variables

\begin{tabular}{|c|c|c|c|c|}
\hline Variables & $\begin{array}{l}\text { Small scale } \\
\text { percentage }\end{array}$ & $\begin{array}{l}\text { Medium scale } \\
\text { percentage }\end{array}$ & $\begin{array}{l}\text { Large scale } \\
\text { percentage }\end{array}$ & $\begin{array}{l}\text { Overall } \\
\text { percentage }\end{array}$ \\
\hline \multicolumn{5}{|c|}{ Gender of beekeepers } \\
\hline Male & 92.00 & 91.70 & 100.00 & 93.30 \\
\hline Female & 8.00 & 8.30 & 0.00 & 6.70 \\
\hline \multicolumn{5}{|c|}{ Ethnicity of the respondents } \\
\hline Brahmins/Chhetri & 44.00 & 41.70 & 45.50 & 43.30 \\
\hline Janajati & 52.00 & 58.30 & 54.50 & 55.00 \\
\hline Dalit & 4.00 & 0.00 & 0.00 & 1.70 \\
\hline \multicolumn{5}{|c|}{ Occupation of $\mathrm{HHH}$} \\
\hline Agriculture & 100.00 & 100.00 & 100.00 & 100.00 \\
\hline Business & 20.00 & 20.80 & 36.40 & 23.30 \\
\hline Service & 4.00 & 20.80 & 18.20 & 13.30 \\
\hline Remittance & 20.00 & 20.80 & 0.00 & 16.70 \\
\hline \multicolumn{5}{|l|}{ Education status } \\
\hline Basic & 12.00 & 12.50 & 0.00 & 10.00 \\
\hline Primary level & 40.00 & 20.80 & 27.30 & 30.00 \\
\hline Secondary level & 40.00 & 54.20 & 18.20 & 41.70 \\
\hline Bachelor level & 8.00 & 12.50 & 45.50 & 16.70 \\
\hline Masters level & 0.00 & 0.00 & 9.10 & 1.70 \\
\hline \multicolumn{5}{|l|}{ Migration status } \\
\hline Migrated & 72.00 & 25.00 & 0.00 & 40.00 \\
\hline Non migrated & 28.00 & 75.00 & 100.00 & 60.00 \\
\hline
\end{tabular}


Table 2: Socio-economic characteristics of continuous variable

\begin{tabular}{lccccc}
\hline Variable & Small scale & Medium scale & Large scale & F value & P value \\
\hline Age & 40.04 & 41.67 & 42.91 & 0.310 & 0.74 \\
Years of experience & 6.20 & 9.71 & 16.18 & $9.15 * * *$ & 0.00 \\
HH size & 5.40 & 5.58 & 6.00 & 0.31 & 0.71 \\
Male members & 2.76 & 2.92 & 3.45 & 1.22 & 0.30 \\
Female members & 2.64 & 2.67 & 2.55 & 0.04 & 0.97 \\
Economically active & 3.68 & 3.71 & 4.27 & 0.70 & 0.50 \\
Dependency ratio & 0.59 & 0.66 & 0.37 & 1.01 & 0.37 \\
Hive number & 37.08 & 69.71 & 171.55 & $140.30^{* * *}$ & 0.00 \\
\hline
\end{tabular}

Note: $* * *$ indicate $1 \%$ level of significance

Table 3: Total cost incurred in different Beekeeping enterprise (in NRs)

\begin{tabular}{llllll}
\hline Particulars & Small & Medium & Large & Average & F value \\
\hline Total Fixed cost & $766.04(15.10)$ & $858.39(18.84)$ & $1130.35(29.54)$ & $869.77(18.32)$ & 0.715 \\
Labor & $720.39(14.20)$ & $379.61(8.33)$ & $234.12(6.12)$ & $494.92(10.43)$ & $20.756 * * *$ \\
Migration cost & $2378.94(46.88)$ & $1869.13(41.02)$ & $1026.56(26.83)$ & $1927.08(40.60)$ & $24.62 * * *$ \\
Drugs cost & $60.11(1.19)$ & $60.99(1.34)$ & $57.53(1.50)$ & $59.99(1.26)$ & 0.022 \\
Feed cost & $559.77(11.03)$ & $657.40(14.43)$ & $840.59(21.97)$ & $758.30(15.98)$ & $14.888 * * *$ \\
Comb foundation cost & $336.88(6.64)$ & $340.79(7.48)$ & $376.68(9.84)$ & $345.74(7.28)$ & 0.184 \\
Repair and maintenance & $74.12(1.46)$ & $60.55(1.33)$ & $39.75(1.04)$ & $62.39(1.31)$ & $4.001 * *$ \\
Marketing & $174.38(3.44)$ & $211.66(4.65)$ & $121.08(3.16)$ & $179.52(3.78)$ & 1.931 \\
Planting bee flora & $4.00(0.10)$ & $118.06(2.59)$ & $0.00(0.00)$ & $48.88(1.03)$ & 1.249 \\
Total variable cost & $4632.89(84.9)$ & $3803.45(81.16)$ & $2318.69(70.46)$ & $3876.84(81.68)$ & $2.40 *$ \\
Total & 5398.93 & 4661.84 & 3449.03 & 4746.62 & \\
\hline
\end{tabular}

Notes: Figures in parenthesis indicate percentage. $* * *, * *$ and $*$ indicates 1,5 and $10 \%$ levels of significance

Table 4: Benefit-cost analysis of honey production in scale of production (in NRs)

\begin{tabular}{lcccr}
\hline Particulars & Small scale & Medium scale & Large scale & Average \\
\hline Total cost/hive & 5398.94 & 4661.84 & 3449.04 & 4746.62 \\
Income/ hive & 6356.61 & 8061.53 & 8981.58 & 7519.82 \\
Gross margin & 1723.72 & 4258.08 & 6662.89 & 3642.97 \\
Net margin & 878.27 & 3399.69 & 5532.54 & 3270.17 \\
B:C Ratio & 1.17 & 1.71 & 2.61 & 1.65 \\
\hline
\end{tabular}

F test value of BC Ratio: 28.429***

Note: $* * *$ indicate $1 \%$ level of significance.

Among the variable cost, labor, migration, feed cost was highly significant at $1 \%$ level among small, medium and large-scale enterprise. Cost of repair and maintenance was moderately significant $(\mathrm{p}<0.05)$ and as a whole total variable cost was found to be low significant $(\mathrm{p}<0.1)$. Meanwhile, depreciation, marketing, drugs and comb cost was found insignificant i.e., three different categories of enterprise have uniform cost on respective items. The average cost of production recorded by (Shrestha, 2018; Dhakal et al., 2015) was found similar to this study. The major variable cost incurred in honey production was migration cost which is different from (Devkota, 2006).

\section{Benefit Cost Analysis}

On an average the productivity of honey was found to be $23.71 \mathrm{~kg} /$ hive which were slightly less than 40.71 $\mathrm{kg} /$ hive stated by (Vaziritabar and Esmaeilzade, 2016). The average total cost/ hive was found to be NRs 4746.62 which gives the return of NRs 7519.82. The overall BC was found to be 1.65 . The similarly, gross margin and net margin was found to be NRs 3642.97 and NRs 3270.17 respectively as shown in Table 4 . The B: $\mathrm{C}$ ratio was found significant with the scale of production at $1 \%$ level of significance. Thus, the result portrays that honey production in the study area is profitable in all categories. However, commercialization and adoption of technologies can provide a high return in case of honey enterprise.

Poudel (2003) reported B:C ratio of honey production slightly higher than this study. However, (Dhakal et al., 2015) had similar result. The findings are also in line with (John et al., 2017). (Mmasa, 2007) also reported beekeeping as a viable enterprise.

\section{Production Function Analysis}

The regression model obtained for honey production is presented in Table 5. The explanatory power of the estimated model for honey production was 0.57 . F ratio being highly significant, the model was a good fit. All the explanatory variables had positive coefficients except migration cost. The Coefficient for the cost of comb foundation was found to be positive and significant at $1 \%$ level of significance indicating that $100 \%$ increase in the use of comb foundation, keeping other factors constant would increase the gross return by $26 \%$. Labor cost seemed to be significant at $1 \%$ level indicating $100 \%$ increase in the labor hours would increase return by $22 \%$ keeping other things constant. Similar was the result of (Dhakal et al., 2017). 
Table 5: Production function analysis

\begin{tabular}{lllll}
\hline Variables & Coefficients & St. Error & t-value & F value \\
\hline Constant & $5.43^{* * *}$ & 0.70 & 7.74 & 0.000 \\
Labor cost & $0.22 * * *$ & 0.64 & 3.40 & 0.001 \\
Migration cost & -0.20 & 0.13 & -1.61 & 1.44 \\
Feed cost & 0.22 & 0.15 & 3.66 & 0.112 \\
Cost of comb foundation & $0.26 * * *$ & 0.72 & 1.83 & 0.157 \\
Marketing cost & $0.13^{*}$ & 0.07 & & 0.001 \\
$\mathrm{R}^{2}$ & 0.57 & & & 0.073 \\
Adjusted $\mathrm{R}^{2}$ & 0.53 & & & \\
F ratio & 14.17 & &
\end{tabular}

Table 6: Resource- use efficiency of various inputs in Beekeeping enterprise

\begin{tabular}{lcccccc}
\hline Inputs & Geometric mean & Coefficient & MVP & MFC & MVP/MFC & Efficiency \\
\hline Labor cost & 494.13 & 0.22 & 3.16 & 1 & 3.16 & Underutilized \\
Migration cost & 1758.25 & -0.20 & -0.80 & 1 & -0.80 & Overutilized \\
Feed cost & 698.53 & 0.22 & 2.24 & 1 & 2.24 & Underutilized \\
Comb foundation cost & 295.21 & 0.26 & 6.26 & & 6.26 & Underutilized \\
Market cost & 147.61 & 0.13 & 6.26 & 1 & 6.26 & Underutilized \\
\hline
\end{tabular}

Similarly, marketing cost showed significance at $10 \%$ level on gross returns from honey production. Keeping all other factors constant, $100 \%$ increase in the market cost would increase the return by $13 \%$. Marketing cost includes the cost incurred during packaging and processing of honey produced which increases the value of honey and gross return rises.

The coefficients of migration were negative and found to be insignificant to gross return. Similarly, feed cost also found to be insignificant. But as reported in the article (Dhakal et al., 2015; Shrestha, 2018), cost of migration, sugar, comb foundations were significant to the returns.

\section{Return to Scale/Elasticity of Production}

The return to scale was found 0.63 which is smaller than one that implies decreasing return to scale i.e., increasing $100 \%$ input can increase output by $63 \%$. Similar, finding was obtained from (Shrestha, 2018; Devkota et al., 2016).

\section{Resource Use Efficiency}

The estimated MVP of different inputs used in honey production is presented in Table 6 . The study revealed that the ratio of MVP to MFC of the labor cost, marketing cost and comb foundation was positive and greater than one indicating their underutilization. The findings were similar to (Al-Ghamdi et al., 2017) similarly, for migration cost was negative and less than one which indicated the overutilization of resources. However, the ratio was negative demonstrated less profit could be derived by increasing migration cost. In the article (Shrestha, 2018; Devkota et al., 2016), all resources were found underutilized.

\section{Conclusion}

Abundant availability of the dense forest, productive lands for crop cultivation favored the beekeeping enterprise. The study showed an increasing trend of hive numbers having an overall productivity of $23.71 \mathrm{~kg} / \mathrm{hive}$. The average cost of production for a small scale was found highest compared to the medium and large scale. Gross margin was found highest in the large scale followed by the medium and small-scale enterprise. Similarly, the benefit cost ratio was found greater than one in every scale enterprise indicating beekeeping as a highly profitable business. The result showed the economy of scale. The cost of labor, migration, feed, marketing, comb foundation and repair and maintenance proved to be significant for the increase in gross return. However, labor and migration costs were negatively significant. Return to scale was 0.63 and reflected the decreasing return to scale. The analysis of resource use efficiency showed that expenditure on labor, feed, Comb foundation and marketing were underutilized. It was suggested to increase human labor, materials use like artificial feeds, comb foundation, better packaging materials for marketing, etc. for optimum profit. There is an ample potential to acquire optimum profit with required adjustment on resources use. This can be possible through subsidies from various agencies, access to loans, extension facilities, insurance, etc.

\section{Acknowledgement}

The authors express their deepest gratitude to the respondents and stakeholders of the study areas for their cooperation in conducting surveys and collecting the data and information. 


\section{Authors Contributions}

Sushmita Bhatta: Participated in research design, data collection, data analysis, manuscript preparation.

Suraksha Baral: Participated in data collection and data analysis.

Jay Prakash Dutta: Participated in manuscript preparation and review.

\section{Ethics}

This article is original and contains unpublished material. The corresponding author confirms that all of the other authors have read and approved the manuscript and no ethical issues involved.

\section{References}

Abebe, A. (2009). Market chain analysis of honey production in Atsbi Wemberta District, eastern zone of Tigray national regional state (Doctoral dissertation, Haramaya University).

Al-Ghamdi, A. A., Adgaba, N., Herab, A. H., \& Ansari, M. J. (2017). Comparative analysis of profitability of honey production using traditional and box hives. Saudi journal of biological sciences, 24(5), 1075-1080.

Aryal, S., Thapa, R., \& Jung, C. (2015). An overview of beekeeping economy and its constraints in Nepal. Journal of Apiculture, 30(3), 135-142.

Bhattarai, S., Nepali, N., Thaller, J., Thewarapperuma, A., \& Webb, J. (2013). Promoting agribusiness innovation in Nepal, feasibility assessment for an agribusiness innovation center. The World Bank: Washington, DC, USA.

Central Bureau of Statistics. (2016). Annual Household Survey 2015/16. Government of Nepal: SinghDurbar, Kathmandu. https://nada.cbs.gov.np/index.php/catalog/85/studydescription

Devkota, K. H. (2006). Benefit-Cost analysis of apiculture enterprise: A case study of Jutpani VDC, Chitwan, Nepal. Journal of the Institute of Agriculture and Animal Science, 27, 119-125.

Devkota, K., Dhakal, S. C., \& Thapa, R. B. (2016). Economics of beekeeping as pollination management practices adopted by farmers in Chitwan district of Nepal. Agriculture \& Food Security, 5(1), 1-6.

Dhakal, S. C., Regmi, P. P., Thapa, R. B., Sah, S. K., \& Khatri-Chhetri, D. B. (2015). Profitability and resource use efficiency of buckwheat (Fagopyrum esculentum Moench) production in Chitwan District, Nepal. Journal of Agriculture and Environment, 16, 120-131.
John, R., Dar, J., Beigh, M. A., Bhat, M. A., \& Dar, I. (2017). Benefit-Cost Analysis of Apiculture Enterprise in District Pulwama and Srinagar. Int. J. Pure App. Biosci, 5(4), 51-53.

Kattel, R. R., \& Sapkota, M. (2018). Brain drain of agriculture and veterinary graduates to abroad: evidence from Nepal. Agriculture \& Food Security, $7(1), 61$.

Mmasa, J. J. (2007). Economic analysis of honey production and marketing in Hai district, Kilimanjaro, Tanzania (Doctoral dissertation, Sokoine University of Agriculture).

MoAD. (2016/17). Statistical Information On Nepalese Agriculture 2073/74 (2016/17) | Ministry of Agriculture and Livestock Development. Singhadurbar, Kathmandu, Nepal. https://opendatanepal.com/dataset/statisticalinformation-on-nepalese-agriculture-2073-74

MoCS, G. (2010). Nepal trade integration strategy 2010: Executive summary and action matrix. Kathmandu: Ministry of Commerce and Supplies, Government of Nepal.

Poudel, L. (2003). Economics of honey production and marketing: A case of Chitwan, Nepal. Chitwan, Nepal: IAAS, Rampur Campus.

SAWTEE. (2015). Nepalese Honey: Potential and Challenges in Export. Lalitpur: Deutsche Gesellschaft für Internationale Zusammenarbeit (GIZ) GmbH.

Shrestha, A. (2018). Study of Production economics and production problems of honey in Bardiya District, Nepal. Sarhad Journal of Agriculture, 34(2), 240-245.

Vaziritabar, S., \& Esmaeilzade, S. M. (2016). Profitability and socio-economic analysis of beekeeping and honey production in Karaj state, Iran. Journal of Entomology and Zoology Studies, 4(4), 1341-1350.

Verma, L.R. (1990). Beekeeping in Integrated Mountain Development: Economic and Scientific Perspectives. Oxford and OBH Publishing Co. Pvt. Ltd. Delhi. 